\title{
Evaluation of Endemic Status of Lymphatic Filariasis in Areas Adjoining to the Endemic District of Bangladesh
}

${ }^{*}$ Halim $\mathrm{KS}^{1}$, Ahmed BN ${ }^{2}$, Nargis $\mathrm{F}^{3}$, Begum F${ }^{4}$, Akhter R ${ }^{5}$, Ferdousi $\mathrm{QH}^{6}$, Ummon $\mathrm{IJ}^{7}$

\begin{abstract}
In Bangladesh, it was assumed that the endemicity of Lymphatic Filariasis (LF) in areas adjoining to the endemic districts may be related to the endemicity of this districts due to presence of sufficient vectors and extend of microfilaria for it's chronicity. LF is caused by nematodes (round worms) and mainly transmitted to man by the infected-Culex mosquito. Among the 3 types of thread-like filarial worms; Wuchereria bancrofti is responsible for $90 \%$ of the cases. Filariasis is endemic in 34 districts and clinical cases are reported from 51 districts, with high endemicity in the northern part of Bangladesh. This cross-sectional survey study was conducted among 6,100 participants at areas adjoining to the endemic districts of LF to evaluate the endemic status during the period of $1^{\text {st }}$ July 2014 to $30^{\text {th }}$ June 2016. Total 10 sub-districts (upa-zilas) were selected from 5 districts of 4 divisions adjoining to the filaria endemic districts, and then 02 sub-districts (Sub-D) from each district. From each Sub-D, 02 unions (several unions constitute a sub-districts) and 10 'spot check site (SCS)' from these unions were selected
\end{abstract}

1. *Prof. Dr. Kazi Shafiqul Halim, Professor \& Head, Department of Epidemiology, National Institute of Preventive and Social Medicine (NIPSOM), Mohakhali, Dahaka-1212. Email: drzimmu_ nipsom@yahoo.com

2. Prof. Dr. Be-Nazir Ahmed, Ex- Director, Communicable Disease Control (CDC), Directorate General of Health Services (DGHS), Mohakhali, Dhaka.

3. Dr. Fatema Nargis, Medical Officer, OSD, DGHS; Attached: BG Press Health Center, Tejgaon, Dhaka.

4. Dr. Ferdoushi Begum, Asst. Professor, Community Medicine, Shahid Tajuddin Ahmad Medical College (STAMC), Gazipur.

5. Dr. Rafia Akhter, Assistant Professor, (Community medicine), STAMC, Gazipu.

6. Dr. Qazi Hena Ferdousi, Asst. Professor, Community Medicine, Govt. Homeopathic Medical College, Dhaka

7. Dr. Israt Jahan Ummon, MPH (Epidemiology), Medical Oficer, Institute of Public Health, Mohakhali, Dhaka

*For correspondence randomly. Villages and nearby areas of the 'SCS' were publicized previous day of data collection by personnel from Upa-zila Health Complexes (UHC) and audio announce. Average 60 samples were collected from each 'SCS' and interviewed participants in the same day. Data were collected by using On Site Filariasis Rapid test cassette for identifying the filarial cases and socioeconomic and demographic data had also been collected by interviewing using questionnaire. The mean age of the participants was 30.03 +14.85 ; female - male ratio of were 1: 0.97 and almost equal numbers (20\%-30\%) respondents were in each age group (5-15, 16-25, 26-40 and $>40$ years). Most of the participants were Muslims and two third were married, where 56\% were completed primary education or could not read and write and $44 \%$ secondary level or above. Nearly three fourth of participants were involved in household/ agricultural works or laborers; others were students, had service and small business and $01 \%$ had no work. Two third of participants had no income or could not state and other had monthly income ranges from 1000 to 10,000 taka. Prevalence rate of LF test positive cases was $0.2 \%$; male-female ratio was 1:3, IgG was detected in $83 \%$ and rest IgM. Two third of cases were in age group 16-25 years and one fourth in $>40$ years; only $8.3 \%$ were in 5-15 years and no cases were found in age group 26-40 years. All positive cases were Muslim and two third were married, where majority were illiterate or primary and rest of them completed secondary or above. Two third of cases did household or agricultural works and rest were students. Two third had no income or could not state, one fourth had $>2000$ to 5000 taka and only $8.3 \%$ had income 5001->10000 taka. The highest prevalence rate (2.50/1000 Pop) were found in Naogaon of Gaibandha districts and sub-districts were Niamotpur o Sadullapur (5.0/1000 Pop) and no cases were detected at Singra (Natore), Porsha (Naogaon), Palashbari (Gaibandha). Two third of cases suffered from itching; majority had fever and cough and one third stated breathlessness. Clinical signs edema was seen in feet $41.7 \%$ of cases. Few cases $08.3 \%$ had reached to health care facilities and $91.7 \%$ cases had never sought diagnostic facilities. Adjoining areas of endemic districts of $L F$ are prone to spread this disease. Routine survey of $L F$ cases would be continued in areas adjoining to the endemic district.

Keywords: Lymphatic filariasis (LF), endemic status, areas adjoining to the endemic districts, spot check site, endemicity of LF, OnSite Filariasis Rapid test. 


\section{INTRODUCTION}

In Bangladesh the National Lymphatic Filariasis Elimination Programme was started in 2001 with an ultimate goal to eliminate Filariasis from Bangladesh by 2015. In 2001, mass drug administration (MDA) was started in one districts and scaled up in 19 districts. Till 2010, 13 out of 19 districts had completed five or more rounds of MDA and Microfilariae (MF) prevalence rates were found to be zero in 5 districts. MF survey (2008-10) reveals the prevalence is $<1 \%$. Recently, the critical issue is to evaluate status of endemicity of area adjoining to the endemic districts in Bangladesh. ${ }^{1}$

The ICT filarial antigen test (Binax) is a rapid immunochromatographic technique (ICT) using specific monoclonal and polyclonal antibodies and one of choice for community surveys and rapid assessment of filarial endemicity ${ }^{2}$.

In May 1997, the $50^{\text {th }}$ World Health Assembly recognized the importance of controlling lymphatic filariasis and passed a resolution calling for "the elimination of lymphatic filariasis as a public health problem" and the International Task Force for Disease Eradication labeled filariasis as one of the six diseases that have the potential to be eliminated by $2020 .^{2}$ LF has been identified by the World Health Organisation (WHO) as the second leading cause of permanent and long-term disability world-wide. ${ }^{3}$

Diethylcarbamazine has been used to treat filariasis since 1947 and global filariasis elimination is annual, mass, community-wide drug administration of this drug. ${ }^{3}$ Ivermectin is equally effective against brugian filariasis. ${ }^{12} \mathrm{~A}$ combination of diethylcarbamazine and ivermectin are very effective in rapid and long-term clearance of microfilariae. ${ }^{3}$

All the mosquitoes- culex, anopheles, mansonia and aedes--spread the disease. ${ }^{5}$ The symptoms of the disease appear after three to seven years of the mosquito bite and the leg, arm, genital organ and breasts become enlarged abnormally. ${ }^{6}$

Government of Bangladesh (GoB) reports, filariasis detected in 32 districts in 2006. But blood test (ICT) by experts had detected the disease in 39 districts in 2006, mostly in border areas, about 5 million poor people had been suffering from LF, locally called 'Godh' and nearly 50 milion people were vulnerable. ${ }^{5}$

Recently filariasis is endemic in 34 districts (based on ICT survey) and clinical cases were reported from 51 districts, with high endemicity in the northern part of the country. It is estimated that 70 million people are at risk of infection in endemic areas and about 20 millions are suffering, most of them are children, while 10 million people are with various forms of clinical deformity and another 10 million people are microfilaremics. ${ }^{7}$ At least one in every ten persons in thirteen northern districts carries filarial parasite. $^{\text {? }}$

There are three types of thread-like filarial worms: Wuchereria bancrofti, which is responsible for $90 \%$ of the cases, Brugia malayi most of the remainder and $B$. timori, may also causes the diseases. ${ }^{8,}{ }^{10}$ Man is the definite host of Bancroftian and Brugian filariasis and it is transmitted to man by the bites of infected mosquitoes - Culex mosquito. Adult filarial worm lives in lymphatic vessels for 6-8 years and microfilariae that circulate in the peripheral blood and are able to infect mosquitoes. This infection causes lymphangitis, lymphadenitis, elephantiasis of genitals, legs and arms. ${ }^{4,10}$

Countries where LF is found are mostly in the tropical and sub-tropical regions of the world. ${ }^{7} \mathrm{LF}$ is endemic in 83 countries including six south Asian countries with over 1.3 billion people at risk of contracting it. ${ }^{6,8,11}$ Globally, over 120 million people are currently infected, with about 40 million disfigured and incapacitated by the disease. ${ }^{5,10}$ Approximately $65 \%$ of those infected live in the WHO South-East Asia Region, 30\% in the African Region, and the remainder in other tropical areas. ${ }^{10}$

\section{METHODOLOGY}

Study design: Cross-sectional survey study.

Study places: Five districts from four divisions adjoining to the filaria endemic districts and then two Sub-Ds from each district.

Study period: $1^{\text {st }}$ July 2014 to $30^{\text {th }}$ June 2016 (02 years).

Sample Size: Six thousand and one hundred $(6,100)$

Sampling Technique: Five (05) adjoining districts were selected purposively out of 29 districts border with the 34 endemic districts. From 05 districts, 02 Sub-Ds had been selected randomly from each district and these Sub-Ds were selected from those Sub-Ds border with the endemic districts, lastly 02 unions were selected randomly among the unions from each selected sub-districts. Among the villages of 02 selected unions 10 'SPSs' were selected randomly. The location of 'SCSs' were fixed at entrance point of the selected village. Villages and nearby area of the selected 'SCSs' 
were publicized previous day by UHC Health Personnel and audio announce. Male female ratio was controlled at almost $1: 1$ and $20 \%$ of children (5 to 15 years) had been included in this survey study. From each 'SCS' average 60 samples have been examined and interviewed in the same day.

Data collection procedure: Data had been collected by using OnSite Filariasis Rapid test cassette (Serum/plasma). One (01) $\mathrm{ml}$ of venous blood was collected by syringe from the left cubital vein and then ICT was done by OnSite Rapid Test for identifying the filarial cases (IgG and IgM antibody for lymphatic filarial parasites). Socioeconomic and demographic data had also been collected by interviewing patients.

Data management and analysis: Data were cleaned first; then data were processed and data entry was done for analysis (single entry of data had been performed). Data had been analyzed by computer using SPSS (Version 19.0).

Ethical implications: The study had been conducted maintaining all possible ethical considerations. Informed written/verbal consent of the respondents had obtained before data collection. Confidentiality of data was ensured strictly and name of participants and cases preserved in computer by anonyminazation and were used only for the purpose of this study. Ethical clearance has been obtained from the Ethical Committee of NIPSOM (National Institute of Preventive and Social Medicine).

\section{RESULTS AND OBSERVATIONS}

\section{A. Distribution of participants in survey $(n=6,100)$ :}

Out of 6100 respondents, 3006(49.3\%) were male and $3094(50.7 \%)$ were female and 93\% was Muslim and rest $7 \%$ was other religion. Among the respondents $66 \%$ was married, $33 \%$ was unmarried and $1 \%$ divorced, separated, widow etc.

The education level of the respondents 35\% primary, $44 \%$ secondary-higher secondary or above level and $21 \%$ could not read and write. By occupation $68 \%$ was household and agricultural works, $12 \%$ student, $14 \%$ service and business, $5 \%$ labor and factory worker, $1 \%$ had no work. Monthly income of the respondents, $67 \%$ had no income or un-responded or could state and $33 \%$ had monthly income 1,000 to $>10,000$ taka.

The mean age of the study subjects was $30.03 \pm 14.85$ years.
Figure-1 shows the distribution by age group. Out of 6100 respondents $1267(20.8 \%)$ were in 5-15 years, 1474 $(24.2 \%), 1603(26.3 \%)$ and $1756(28.8 \%)$ were in $16-25$, $26-40$ and $>40$ years repectively.

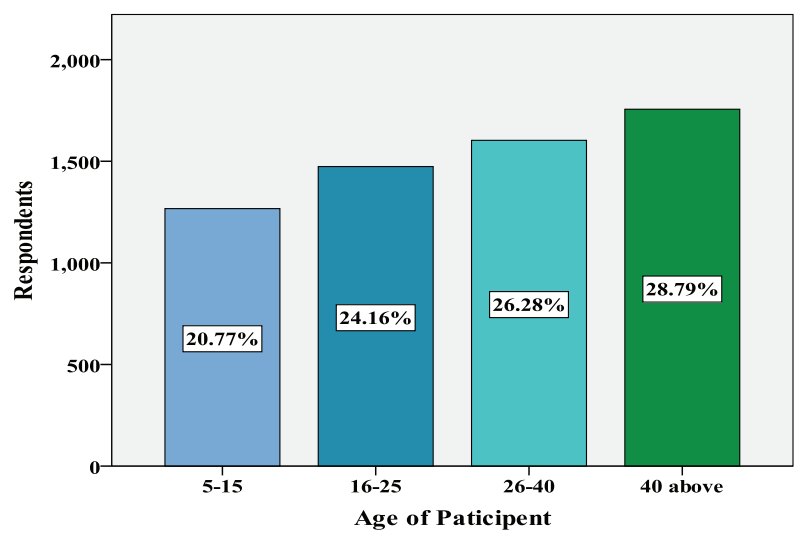

Figure-1: Age of respondents in survey $(n=6,100)$

\section{B. Distribution of respondents by 'Rapid Test result of blood examination $(n=12)$.}

Out of 12 cases, $\operatorname{IgG}$ was detected in $10(83 \%), \operatorname{IgM}$ in 02(17\%). Distribution by sex, 03(25.0\%) were male and $09(75.0 \%)$ were female.

Table 1 shows the distribution of cases by age groups, $01(8.3 \%)$ were in $5-15,08(66.7 \%)$ and $03(25.0 \%)$ were in $16-25$ and $>40$ years respectively. No cases were in age group $26-40$ years.

Table 1: Age distribution of test positive cases $(n=12)$

\begin{tabular}{|l|c|c|}
\hline Age (Years) & Frequency & Percent \\
\hline $5-15$ & 01 & 8.3 \\
\hline $16-25$ & 08 & 66.7 \\
\hline $26-40$ & 00 & 00 \\
\hline$>40$ & 03 & 25.0 \\
\hline Total & 12 & 100.0 \\
\hline
\end{tabular}

Table 2-5: The distribution of cases- by marital status (Table- 2), 08(66.7\%) were married, 03(25.0\%) were unmarried and 03(8.3\%) were separated. By level of education (Table-3), Illiterate, Primary or Equivalent 07(58.3\%), secondary 04(33.3\%) and higher secondary were $01(8.3 \%)$. By occupation (Table-4), students 04(33.3\%), agricultural works 01(8.3\%) and household works was $07(58.3 \%)$. By monthly income (Table-5), 
$08(66.7 \%)$ had no income or could not state, $01(8.3 \%)$ had income less than 2000 taka, 02(16.7\%) had income 2001 - 5000 taka and 01(8.3\%) had income 5001 $>10000$ taka.

Table 2-5: Distribution of test positive cases by marital status, education, occupation, monthly income

Table 2

\begin{tabular}{|l|c|c|}
\hline Marital Status & Frequency & Percent \\
\hline Married & 08 & 66.7 \\
\hline Unmarried & 03 & 25.0 \\
\hline Separated & 01 & 8.3 \\
\hline Total & 12 & 100.0 \\
\hline
\end{tabular}

Table 3

\begin{tabular}{|l|c|c|}
\hline Education & Frequency & Percent \\
\hline Illiterate, Primary or Equivalent & 07 & 58.3 \\
\hline Secondary or Equivalent & 04 & 33.3 \\
\hline Higher Secondary or equivalent & 01 & 8.3 \\
\hline Total & 12 & 100.0 \\
\hline
\end{tabular}

Table 4

\begin{tabular}{|l|c|c|}
\hline Occupation & Frequency & Percent \\
\hline Student & 04 & 33.3 \\
\hline Agricultural work & 01 & 8.3 \\
\hline Household work & 07 & 58.3 \\
\hline Total & 12 & 100.0 \\
\hline
\end{tabular}

Table 5

\begin{tabular}{|l|c|c|}
\hline Monthly Income & Frequency & Percent \\
\hline No Income & 08 & 66.7 \\
\hline$<=2000$ & 01 & 8.3 \\
\hline $2001-5000$ & 02 & 16.7 \\
\hline $5001-10000$ & 01 & 8.3 \\
\hline Total & 12 & 100.0 \\
\hline
\end{tabular}

Table- 6 shows the prevalence rate of test positive individuals of districts and Sub-Ds adjoining to the endemic districts. The prevalence rate of Tangail district 1.54/1000 Pop, Natore \& Madaripur districts 1.67/1000 Pop and Naogaon \& Gaibandha districts were 2.50/1000 Pop. In Sub-Ds, the prevalence rate 5.0/1000 Pop at Niamotpur \& Sadullapur and 3.3/1000 Pop at Gurudaspur. 1.67/1000 Pop at Gopalpur, Kalkini and Madaripur Sadar. 1.43/1000 Pop at Madhupur and there were no test positive case at Singra, Porsha, Palashbari.

Table 6: Prevalence of test positive cases of districts and Sub-Ds adjoining to the endemic districts (n= 12)

\begin{tabular}{|c|c|c|c|c|c|c|}
\hline Division & $\begin{array}{l}\text { Adjoining } \\
\text { District }\end{array}$ & $\begin{array}{c}\text { PR (Per } \\
1000 \text { Pop.) }\end{array}$ & $\begin{array}{l}\text { Adjoining } \\
\text { Sub-Ds }\end{array}$ & $\begin{array}{c}\text { Test } \\
\text { Positive }\end{array}$ & $\begin{array}{l}\text { Study } \\
\text { Pop. }\end{array}$ & $\begin{array}{c}\text { PR (per } \\
1000 \text { Pop) }\end{array}$ \\
\hline \multirow[t]{2}{*}{ Dhaka } & \multirow{2}{*}{ Tangail } & \multirow{2}{*}{$02(1.54)$} & Gopalpur & 01 & 600 & 1.67 \\
\hline & & & Madhupur & 01 & 700 & 1.43 \\
\hline \multirow[t]{2}{*}{ Rajshahi } & \multirow[t]{2}{*}{ Natore } & \multirow[t]{2}{*}{$02(1.67)$} & Gurudaspur & 02 & 600 & 3.33 \\
\hline & & & Singra & 00 & 600 & 0.00 \\
\hline \multirow[t]{2}{*}{ Rajshahi } & \multirow{2}{*}{ Naogaon } & \multirow[t]{2}{*}{$03(2.50)$} & Porsha & 00 & 600 & 0.00 \\
\hline & & & Niamotpur & 03 & 600 & 5.00 \\
\hline \multirow[t]{2}{*}{ Rangpur } & \multirow[t]{2}{*}{ Gaibandha } & \multirow[t]{2}{*}{$03(2.50)$} & Palashbari & 00 & 600 & 0.00 \\
\hline & & & Sadullapur & 03 & 600 & 5.00 \\
\hline \multirow[t]{2}{*}{ Barisal } & \multirow[t]{2}{*}{ Madaripur } & \multirow[t]{2}{*}{$02(1.67)$} & Kalkini & 01 & 600 & 1.67 \\
\hline & & & Madaripur Sadar & 01 & 600 & 1.67 \\
\hline 4 Divisions & 5 Districts & 12 & & 12 & 6100 & \\
\hline
\end{tabular}

(PR- Prevalence Rate; Pop- Population) 


\section{Clinical manifestation among test positive cases $(n=$} 12):

Table-7.1 shows the clinical symptoms of cases, out of 12 , $08(66.7 \%)$ were suffering from itching of body, 07 (58.3\%) from occasional fever, 07 (58.3\%) from cough and $04(33.3 \%)$ were suffering from breathlessness. Table-7.2 shows the present clinical signs edema, out of 12 cases, 05(41.7\%) had edema in feet and 07 (58.3\%) had no sign of edema.

Table-8 shows the health seeking behavior of cases, out of 12 cases, only $01(08.3 \%)$ had reached to government hospital, diagnostic facilities and investigation processes while $11(91.7 \%)$ had never seek health facilities.
Table 7.1: Acute clinical symptoms in positive cases $(n=12)$

\begin{tabular}{|l|c|c|}
\hline Symptoms & Frequency & Percent \\
\hline Itching of body & 08 & 66.7 \\
\hline Occasional fever & 07 & 58.3 \\
\hline Cough & 07 & 58.3 \\
\hline Breathlessness & 04 & 33.3 \\
\hline
\end{tabular}

Table 7.2: Edema commonly seen in positive cases $(n=12)$

\begin{tabular}{|l|c|c|}
\hline Edema commonly seen in & Frequency & Percent \\
\hline Feet & 05 & 41.7 \\
\hline No signs & 07 & 58.3 \\
\hline
\end{tabular}

Table 8: Health seeking behavior, name of investigations done and place of diagnosis of positive cases $(n=12)$

\begin{tabular}{|l|l|lcc|}
\hline $\begin{array}{l}\text { Health seeking } \\
\text { behavior }\end{array}$ & $\begin{array}{l}\text { Place of } \\
\text { diagnosis }\end{array}$ & $\begin{array}{l}\text { Name of } \\
\text { investigations done }\end{array}$ & Frequency & Percent \\
\hline Government hospital & Government hospital & CBC and ESR & 01 & 08.3 \\
\hline No where & First Time by this survey & No Investigations & 11 & 91.7 \\
\hline
\end{tabular}

\section{DISCUSSION}

The cross-sectional survey study was conducted among 6,100 populations from 10 Sub-Ds (Two from each district) of 5 districts adjoining to the filarial endemic areas in Bangladesh.

In this survey females were higher than male and most of them were Muslim; where two third of respondents were married. The mean age of the participants was $30.03 \pm 14.85$ years and almost uniform distribution of respondents ranges from $20 \%$ to $30 \%$ were found in different four age group of 5-15, 16-25, 26-40 and >40 years.

The educational status of respondents was low in compare with other similar community of Bangladesh, more than half of them completed primary education or could not read and write others were secondary or above. Household and agricultural workers were more than two third of the respondents, only $12 \%$ were students, $14 \%$ were in service and business, rest were labors/ factory workers or had no work. As this study was conducted mostly in the rural area and most of most of the respondents were female, student and unemployed, for this, more than two third had no income or un-responded or could not state. Other one third had monthly income ranges from one thousand to more than ten thousand takas.

The prevalence rate was $2 / 1000$ Pop were found among the surveyed population. Terms of reference (TOR) of National Lymphatic Filariasis Elimination Programme (NLFEP) stated from MF survey (2008-10) reveals the prevalence is < $1 \%{ }^{1}$. This rate is almost similar to this survey rate in areas adjoining to the endemic districts. But we recognize from review article of Hossain MM from there the highest rates of infection and disease are in the northern part of the country where up to $16.8 \%$ of the population is MF-positive and $10.1 \%$ have chronic disease. ${ }^{19}$

Among the cases, IgG was detected in ten cases (83\%) and IgM in rest two $(17 \%)$, consequently antibody titer is needed for confirmation of active and persistent case of Lymphatic Filariasis. These study findings may be crucial to slow and steady transmission of LF from endemic area to its' nearby and adjoining areas. ${ }^{2}$

The study observes the equal distribution of cases ranges between 2 to 3 in each study district and same size of study population adjoining to the corresponding endemic areas ${ }^{1}$. 
The highest prevalence rate was observed in Naogaon \& Gaibandha districts and at Niamotpur and Sadullapur Sub-Ds and no case was found at Singra, Porsha, Palashbari Sub-Ds.

The entire cases were Muslim in religion, among them three fourth of them are female and two third were married. Here more than half of cases were illiterate or primary or equivalent and rest of them were secondary or higher secondary level of education. Two third of cases were involved in agricultural and household work, rest of them were students. The small number test positive cases may not representative in districts.

Most of the test cases live in proverty. Among the cases two third had no income or could not state and rest had monthly income $<2000$ to 5000 taka or more. This finding similar to the report of The Global Alliance to Eliminate Lymphatic Filariasis, The Socio-Economic Impact of LF and the Program to Eliminate It, "Lymphetic Filariasis and Poverty". From this we know "LF is a disease of poverty. In 2003, World Bank classified (80\%) of LF endemic countries as low or lower-middle income countries ${ }^{16}$.

Majority of the cases were young adult $\&$ children. Out of total cases three fourth were in age group 16-25 \& 5-15 years and rest one forth were above 40 years. There no case detected in age group 26-40 year. Statement of Financial Express' Friday June 24, 2005 "about 20 million people of the endemic area suffering from the disease, most of them are children." This study finding is similar to the statement that most of the cases were in age group 5-25 years ${ }^{6}$.

The observation of result shows poor awareness on LF among study community, as of health seeking behavior, information on place of diagnosis and knowledge on investigations were found a few cases and most of them had no awareness. The low level of education may influence these events.

The relative sensitivity and specificity of OnSite Filariasis IgM Rapid Test is $95.8 \%$ and $100 \%$ respectively, where in case of $\operatorname{IgG}$ relative sensitivity and specificity is $92.3 \%$ and $100 \%$ respectively ${ }^{14}$. So there is chance of false negative case detection.

\section{CONCLUSION:}

It was assumed that the prevalence of LF in the sub-districts adjoining to the endemic districts seem to be similar to the endemic districts. Ultimate study result shows the reasonable prevalence of Lymphatic Filariasis in study areas. But sub-districts of highest prevalence rate may have some other associated factors for transmission of microfilarias. This study revealed that young adult \& children are being mostly infected and losing their productive life. Here missing of filarial infection in middle age group (26-40 year) and 3 times more infectivity in female than male is an issue of further study. Findings of poor health seeking behavior indicate the scarce of awareness on LF in study community and drawback of programme planning. Majority of cases had no income or could not state stipulate the proverty situation of the study population.

\section{RECOMMENDATIONS}

This survey study contains remarkable academic, program implementation and policy implication. Following recommendations can be made in the area adjoining to the endemic districts to interrupt incidence: (1) Surveillance for identifying the mode of transmission and size of spread to interrupt incidence of LF, (2) ICT (Spot test for W. bancrofti Antigen) test should be done among young adult \& children for screened out of their exact prevalence. (3) Preventive measure (assure use of mosquito net/LLIN for every individual, routine indoor residual spry, early case detection, existing case searching and treatment) should be taken to interrupt transmission of infection and to combat the further spread and transmission of LF.

\section{CONFLICT OF INTEREST}

This survey study was conducted with technical support of Communicable Disease Control (CDC), Directorate General of Health Services (DGHS), Mohakhali, Dhaka1212.

\section{REFERENCES}

1. Terms of Reference (TOR) from Deputy Program Manager (DPM), National Lymphatic Filaria Elemination Programme (NLFEP), Bangladesh, Communicable Disease Control (CDC), Directorate General of Health Services (DGHS), Bangladesh.

2. Elimination of Lymphatic Filariasis as a Public Health Problem; 1997; Fiftieth World Health Assembly; WHA50.29; Agenda Item 20; Ninth Plenary Meeting, 13th May 1997; A50/VR/9.

3. Wayne D. Melrose, Lymphatic Filariasis Support Centre, School of Public Health and Tropical Medicine, James Cook University, Townsville, QLD 4811, Australia. International Journal for Parasitology 32 (2002) 947-960 
4. 'The Independent' Thursday 17 October, 2011 (A renowned daily English Newspaper published from Dhaka, Bangladesh). Source: Institute of Allergy and Clinical Immunology of Bangladesh (IACIB)

5. 'The Daily Star' Monday 27 March, 2006. Vol. 5 Num 650 (A popular Daily Newspaper of Bangladesh)

6. 'Financial Express' Friday June 24, 2005. Source: Xinhua

7. National Guideline and Strategies for Elimination of Lymphatic Filariasis, Bangladesh, October 2010, Filariasis Elimination Programme, Disease Control Unit, Directorate General Health Services (DGHS), Ministry of Health and Family Welfare, Bangladesh.

8. All About LF, Global Alliance to Eliminate Lymphatic Filariasis, Source: http://www.filariasis.org/all _about_lf_index.html.

9. Naimul Haq, Report- One in every 10 in N-dists has Filaria, Sustainable Development Networking Programme (SDNP), UNDP, Bangladesh.

10. Lymphatic Filariasis, Fact sheet $\mathrm{N}^{\circ} 102$, Updated March 2011, Media centre, World Health Organization (WHO).

11. Policy Brief: Lymphatic Filariasis (LF); CS219919-B, Centre for Global Health, Division of Parasitic Disease and Malaria, CDC, Atlanta, USA.

12. Ottesen et al., 1990; Campbell, 1991; Zheng et al., 1991a,b; Ismail et al., 1991, 1996; Addiss et al., 1993; Kazura et al., 1993b; Coutinho et al., 1994; Ottesen and Campbell, 1994; Nguyen et al., 1994;
Chodakewitz, 1995; Moulia-Pelat et al., 1995, 1996; Ottesen and Ramachandran, 1995; Cao et al., 1997) W.D. Melrose / International Journal for Parasitology 32 (2002) 947-960953.

13. Lammie et al., 1991; Hightower et al., 1993; Steel et al., 1994.

14. Dasgupta, 1984; Partono, 1987; Ottesen, 1989, 1992, 1993, 1994; Evans et al., 1993; Roberts and Janovy, 1996.

15. Literature CTK, Biotec.Inc. Catalog Number R0150C.

16. Moses J. Bockarie, Erling M. Pedersen, Graham B. White, and Edwin Michael" "Role of Vector Control in the Global Program to Eliminate Lymphatic Filariasis Annual Review of Entomology" Vol. 54: 469-487 (Volume publication date January 2009) First published online as a Review in Advance on September 17, 2008 DOI:10.1146/annurev.ento. 54.110807 .090626$.

17. The Socio-Economic Impact of LF and the Program to Eliminate It, "Lymphetic Filariasis and Poverty" (6 - Feb - 04), The Global Alliance to Eliminate Lymphatic Filariasis.

18. Melrose, Wayne D "Lymphatic Filariasis; A Review 1862-2002”; Book, (C) 2004 by Rev'd. Dr. Wayne Melrose; Warwick Educational Publishing Inc; 1st Mar 2004.

19. Hossain MM "Elimination of Lymphatic Filariasis from Bangladesh: Current Status" Journal of Science Foundation, January 2016, Vol. 14, No.1 